\title{
GEOMETRIC DIMENSIONING AND TOLERANCING (GD\&T) OF CONCAVE AND CONVEX FORMS IN THE MILLING OF POLYMERS
}

\author{
M. P. CALVO ${ }^{1}$, JULIÁN R. CAMARGO L. ${ }^{2}$ \& OSCAR D. FLÓREZ C ${ }^{3}$ \\ ${ }^{1}$ Mechanical Engineering Faculty, Universidad Nacional de Colombia, Bogotá \\ ${ }^{2,3}$ Engineering Faculty, Universidad Distrital Francisco José de Caldas, Bogotá
}

\begin{abstract}
Milling polymers have particular complications, especially for their low machining temperatures, so it is important to have the optimal variables to obtain the best nominal value for the final manufactured product. This article compares the engineering tolerance for two different milling strategies, parallel "Raster" and spiral trajectories, to machining concave and convex forms.

This investigation concludes, for machining concave forms either Raster or spiral trajectories have good shape tolerance. On the other hand, for machining convex forms spiral trajectory showed the best engineering tolerance, getting a nominal radius closer to the theoretical radius than the Raster trajectory.

KEYWORDS: Machining Strategy, Raster, Spiral, Tolerance \& Trajectory
\end{abstract}

Received: Jun 08, 2020; Accepted: Jun 28, 2020; Published: Sep 03, 2020; Paper Id.: IJMPERDJUN20201044

\section{INTRODUCTION}

The actual society has progressed so fast that its need for products has increased in the last years. For this reason, manufacturing techniques need to advance, and they need to be more precise to avoid mistakes during the manufacturing process, faults that result in monetary costs, more time in the manufacturing process, or having a not well-done final product. Some of these errors can be avoided by controlling the machining variables, like cutting speed, cutting direction, or tool trajectory.

Mechanical products before becoming a real product have ideal shape parameters, if everything is done in the best way possible, the final result will have all the characteristics desired. But in the manufacturing process, some manufacturing errors cost accuracy in the ending product especially on the geometrical features [1].

Manufacture process can't produce components that have exactly the nominal value assigned, for this reason, it is important to select the best manufacturing strategies, cutting speed, tool, or trajectory [2], [3]. Additionally, machining parameters, like the radius or shape can be affected by the cutting forces, that can be stabilized by the machining strategy [4].

Milling has two main machining strategies, Raster and Spiral. These are going to be the parameter that leaves the mark on the surface of the product, influencing in the final shape and nominal value [5], [6].

Raster strategy is made doing parallel movements of predefined lines. This strategy is mostly used due to the good operation time that presents, is a "simple" strategy and is fast to calculate for the computer; On the other hand, this strategy presents a significant variation of the contact arc, particularly in the corners and in segments with 
a change of direction [7].

The spiral strategy consists in doing spiral movements with the tool in the cutting process. This technique allows better machining in the corners of the working piece, and it is efficient for 2D pockets; Also, it has some advantages, such as a smooth trajectory and a constant cutting direction [8].

Milling polymers have some difficulties, the material can melt during the milling process; furthermore, the polymers can reach their glass transition temperature, resulting in different mechanical properties of what was expected for the final product. If the element melts during the process, it will affect directly in the final shape of the product, causing subsequent problems in the manufacturing process. These are the main reason why adequate manufacturing variables most be chosen [2], [9], [10].

\section{TECHNIQUES}

The measurement was made using the Video Standard Gage system VISUAL 250®. This is LASER equipment, with a coordinate dimension table, $\mathrm{x}$ and $\mathrm{y}$; moving lens, $\mathrm{z}$-direction movement, and optical zoom from $0.7 \mathrm{X}$ to $4.5 \mathrm{X}$. The measure and result was analyzed using TESA-VISTA® software. This software allows a quick evaluation of the geometry of the piece [11].

The material used for the analysis was PEEK KETRON 1000® [10], poly-ether-ether-kethone, a polymer made and distributed by Quadrant Company. This is a thermoplastic with no reinforcement, high chemical resistance, hydrolysis similar to PPS6 [12]. All the measurands were made form the same batch [13]. The material characteristics are shown in Error! Reference source not found..

Table 1: Mechanical Properties [13]

\begin{tabular}{|l|c|}
\hline \multicolumn{1}{|c|}{ Property } & Value \\
\hline Fracture Strain & $40 \%$ \\
\hline Tensile modulus & $4,34 \mathrm{GPa}$ \\
\hline Compressive strength & $138 \mathrm{MPa}$ \\
\hline Yield strength & $110 \mathrm{GPa}$ \\
\hline
\end{tabular}

Measures were made using five test replicas for each testing form. The geometrical forms used for testing were concave and convex.

All the tested pieces were manufactured using a KDMB06M0ERLDK115M insert, sold by Kennametal company [14]. This is a carbide insert of premium quality, with high resistance to damage to non-ferrous materials, can be used, also, in polymers. The carbide insert is shown in Error! Reference source not found. and its characteristics in Error! Reference source not found.

Table 2: Insert Characteristics [14]

\begin{tabular}{|c|c|c|c|}
\hline Insert Reference & $\mathbf{W}(\mathbf{m m})$ & $\mathbf{S}(\mathbf{m m})$ & $\mathbf{R C}(\mathbf{m m})$ \\
\hline KDMB06M0ERLDK115M & 6.00 & 1.60 & 3.0 \\
\hline
\end{tabular}



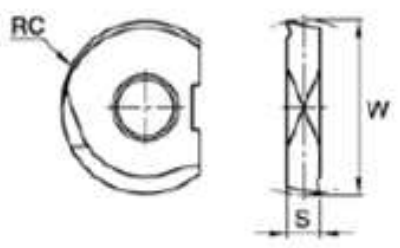

$\mathrm{KDMB}^{\mathrm{TM}}$

Indexable inserts . KDMB.

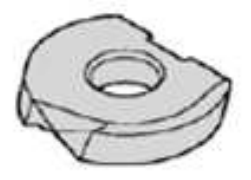

\section{$\mathrm{KDMB}^{\mathrm{TM}}$}

Indexable inserts - KDMB.

Figure 1: Insert Shape [14].

The mounting insert was an HSS, it is shown in Error! Reference source not found., this gave stability and precision to the machining process. All measurands were machined in a CNN milling machine Leadwell V-20i, with 3dimensional moving coordinates [15].
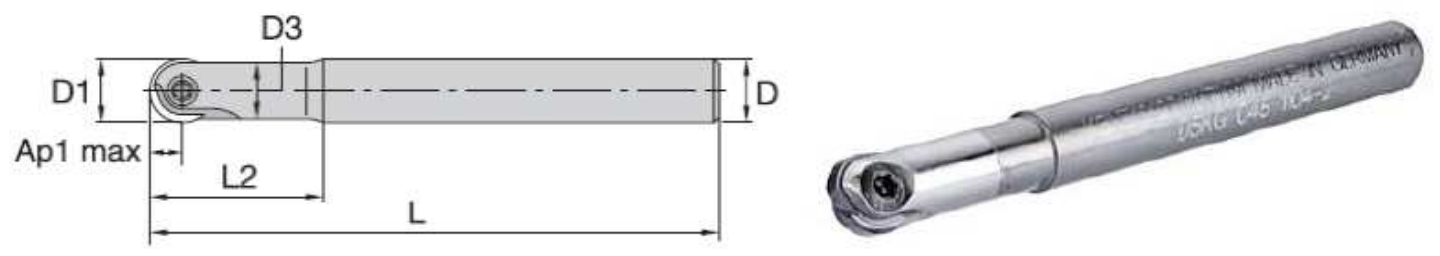

Figure 2: HSS Mounting Insert [14].

The statistical technique used in this investigation was mean difference, using the data obtained from the radios tested for each technique through optical analysis. The statistical analysis was made using R statistics $囚, 3.1 .3$ version.

\section{METHOD}

Measurands were machined with a $25,4 \mathrm{~mm}$ of diameter, a convex and concave form, each of these forms had a theoretical radio of $6.36 \mathrm{~mm}$, as shown in Error! Reference source not found.
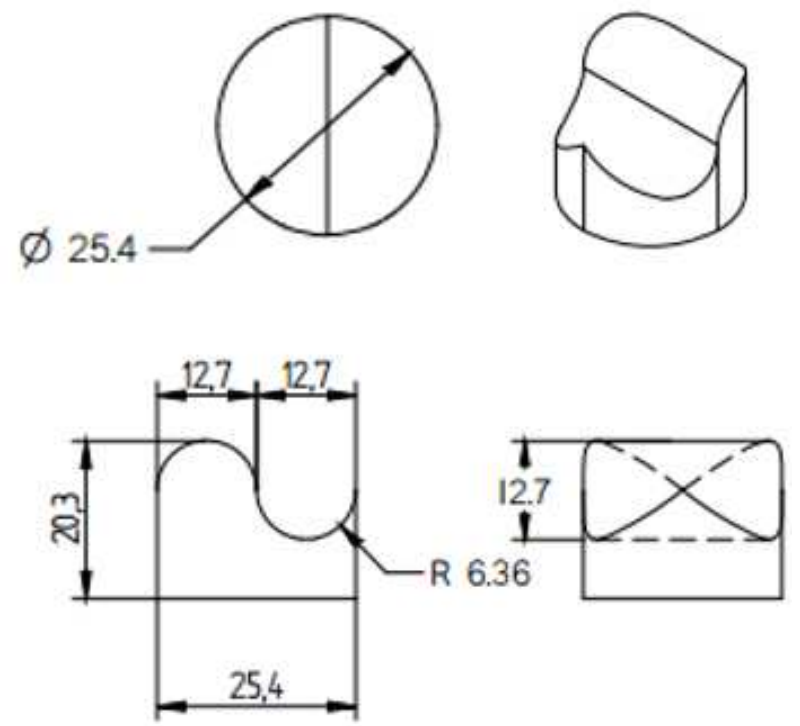

Figure 3: Measurand's Geometrical Characteristics.

Measurands were manufactured using two different trajectories, Raster (parallel trajectory), and spiral, these trajectories are shown in figure 4 . 

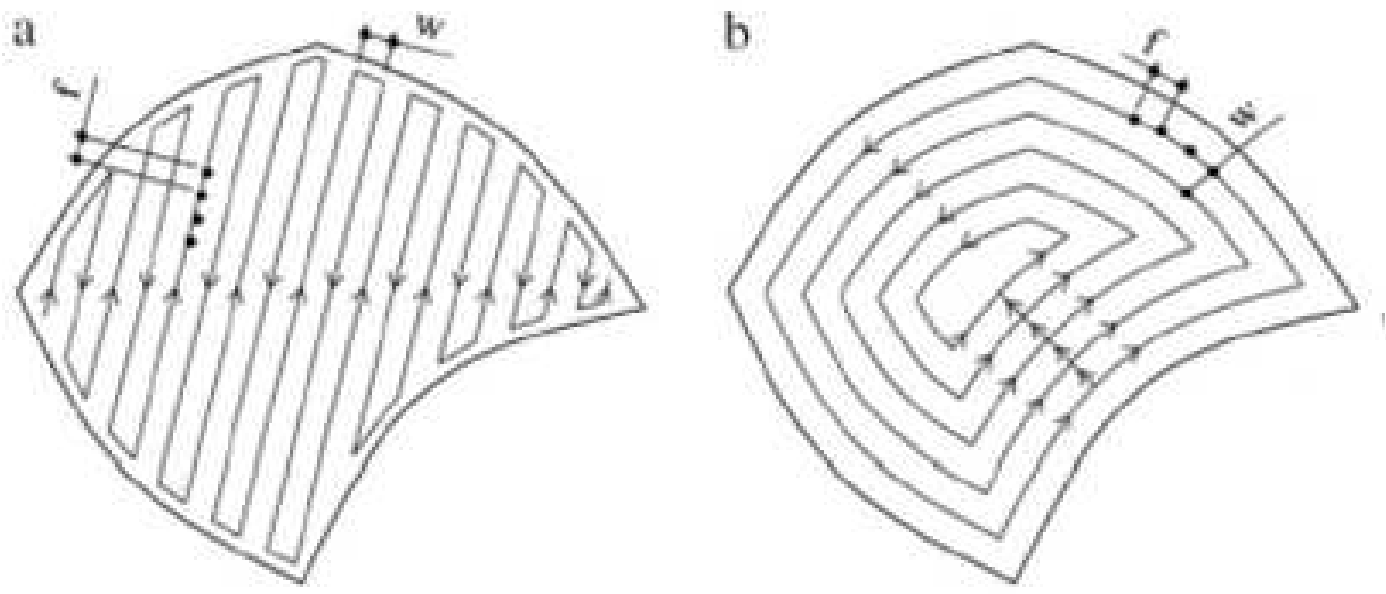

Figure 4: a) Parallel Trajectory “Raster”, b) Spiral Trajectory.

\section{RESULTS}

To determine which trajectory has the best engineering-tolerance, a statistical mean comparison was made using the results obtained through optical measurements.

Results obtained from the measurements taken are shown in Error! Reference source not found. and Error! Reference source not found.

Table 3: Results of each Technique for Convex Shapes

\begin{tabular}{|l|c|c|c|c|c|}
\hline \multicolumn{1}{|c|}{ Technique } & Raster & & & & \\
\hline Radius (mm) & 6,321 & 6,302 & 6,304 & 6,249 & 6,278 \\
\hline Technique & Spiral & & & & \\
\hline Radius (mm) & 6,328 & 6,339 & 6,357 & 6,348 & 6,336 \\
\hline
\end{tabular}

Table 4: Results of each Technique for Concave Shapes

\begin{tabular}{|l|c|c|c|c|c|}
\multicolumn{1}{|c|}{ Technique } & Raster & & & & \\
\hline Radius (mm) & 6,382 & 6,372 & 6,360 & 6,370 & 6,380 \\
\hline Technique & Spiral & & & & \\
\hline Radius (mm) & 6,382 & 6,386 & 6,371 & 6,362 & 6,370 \\
\hline
\end{tabular}

The radius obtained from convex shape was called radius $\mathrm{A}$, and, in the same way, the radius obtained from concave was radius B for the forehead analysis. This notation is shown in Error! Reference source not found. 


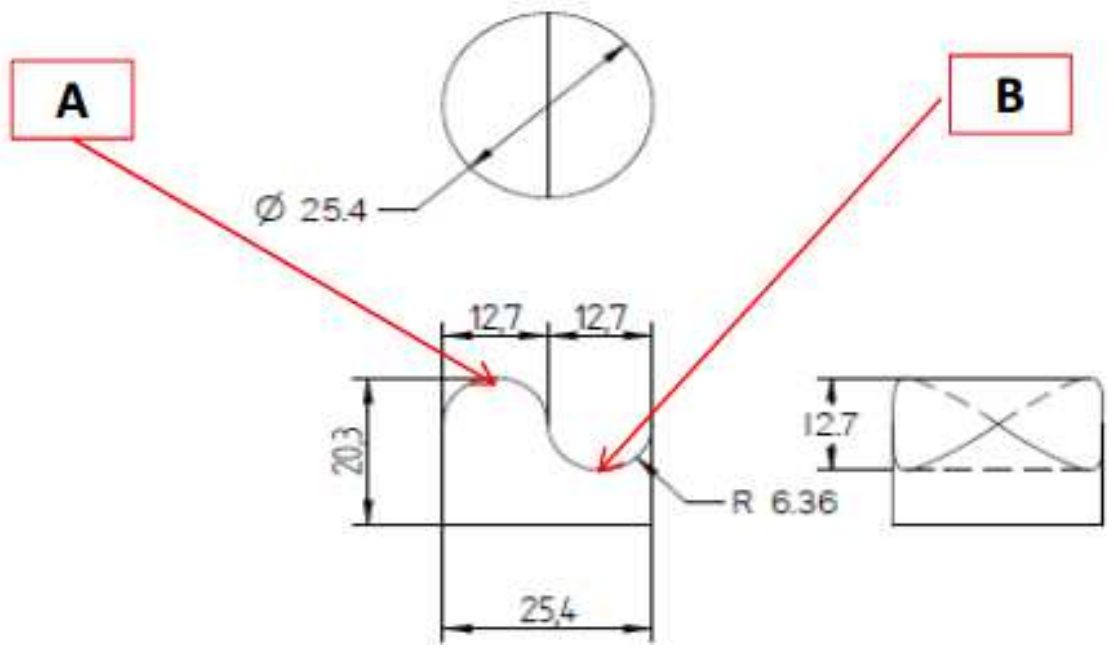

Figure 5: Notation for Radius.

For the analysis, a Tukey's range test with a confidence coefficient of 95\% was done. Results ANOVA [16], [17] are shown in Error! Reference source not found. and Error! Reference source not found.

\section{One-way ANOVA: Radius versus Technique}

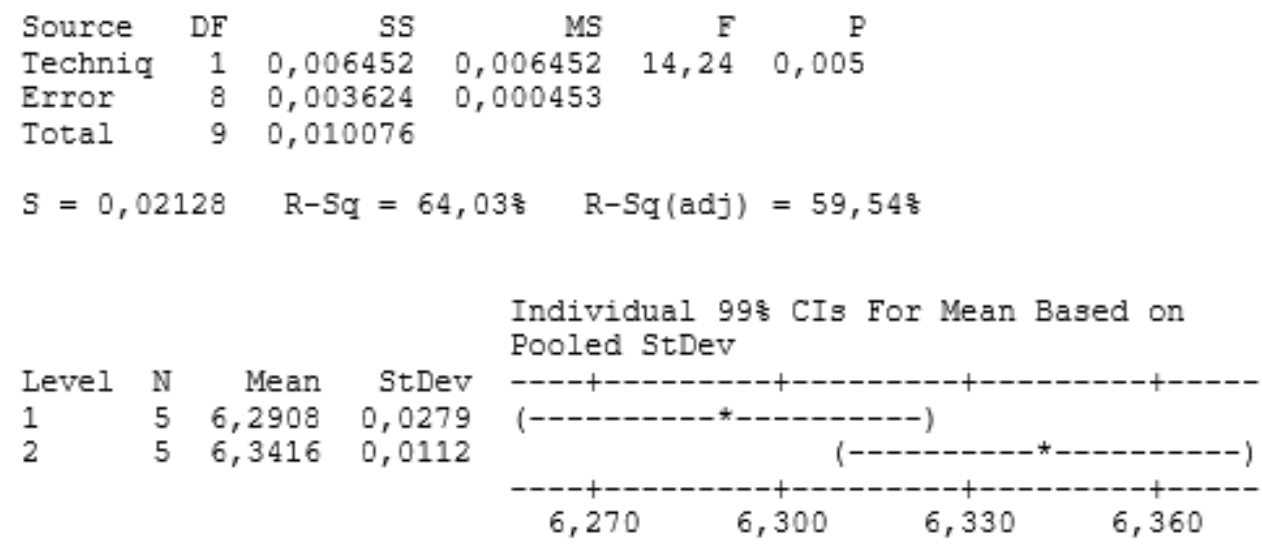

Pooled StDev $=0,0213$

Grouping Information Using Tukey Method

$\begin{array}{llrc}\text { Technique } & \text { N } & \text { Mean } & \text { Grouping } \\ 2 & 5 & 6,34160 & \text { A }\end{array}$

$156,29080 \quad$ B

Means that do not share a letter are significantly different.

Tukey 95\% Simultaneous Confidence Intervals

All Pairwise Comparisons among Levels of Técnica

Figure 6: ANOVA Tukey's Range Test for the Convex Shape. 
One-way ANOVA: Radius versus Technique

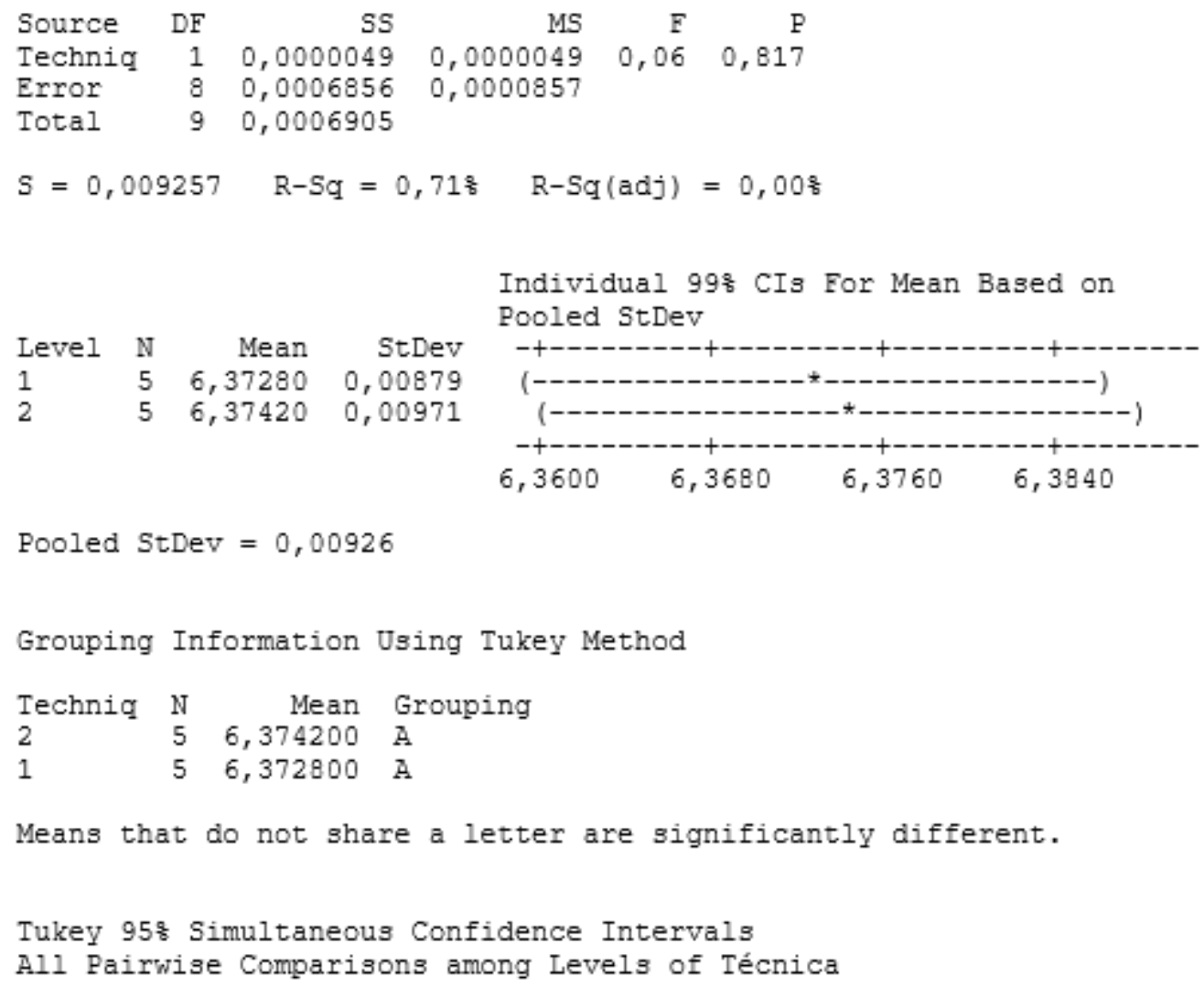

Figure 7: ANOVA Tukey's Range Test for the Concave Shape.

The analysis shows, for machining convex shapes, the spiral technique has the biggest engineering tolerance, compared to the raster technique. For concave forms, there weren't significant differences found between techniques. Both trajectories provide values close to the nominal radius value.

\section{CONCLUSIONS}

For the machining of the polymer material PEEK, this study concludes:

For machining convex form, the spiral trajectory offers the best engineering tolerance. The Raster trajectory presented a bigger standard deviation, and its average measurement was $6.29 \mathrm{~mm}$ compared to the average measurement of the spiral technique $6.34 \mathrm{~mm}$.

For concave shapes, either Raster or Spiral trajectories provide an acceptable engineering tolerance, there's not enough evidence to confirm that one trajectory is better than the other. This can be concluded, due to similar results obtained. The average radius obtained for the Raster technique was $6.37 \mathrm{~mm}$, which was the same value obtained for the Spiral technique, with a standard deviation of 0,0198 .

\section{ACKNOWLEDGMENTS}

The authors would like to thank the Universidad Nacional de Colombia and Universidad Distrital Francisco José de Caldas and to research groups GIBM and LASER that supported the development and testing of the project. 


\section{REFERENCES}

1. Shao, N., Ding, X., \& Liu, J. (2020). Tolerance analysis of spur gears based on skin model shapes and a boundary element method. Mechanism and Machine Theory, 144, 103658. https://doi.org/10.1016/j.mechmachtheory.2019.103658

2. Wang, B., Wei, S., Wang, Y., Liang, Y., Guo, L., Xue, J., ... Xu, B. (2018). Effect of milling time on microstructure and properties of Nano-titanium polymer by high-energy ball milling. Applied Surface Science, 434, 1248-1256. https://doi.org/10.1016/j.apsusc.2017.11.265

3. Napolitano, Salvatore, and Antonio Ascione. "Performance Posture Correlation: A Study in the Women'sWater Polo." International Journal of Humanities and Social Sciences (IJHSS) 6.6 (2017): 53-62.

4. Wang, Y., Calhoun, S., Bosman, L., \& Sutherland, J. W. (2019). Tolerance allocations on products: A life cycle engineering perspective. Procedia CIRP, 80, 174-179. https://doi.org/10.1016/j.procir.2019.01.089

5. Plaza, M., Zębala, W., \& Matras, A. (2019). Decision system supporting optimization of machining strategy. Computers and Industrial Engineering, 127, 21-38. https://doi.org/10.1016/j.cie.2018.11.034

6. Lasemi, A., Xue, D., \&Gu, P. (2010). Recent development in CNC machining of freeform surfaces: A state-of-the-art review. CAD Computer Aided Design. https://doi.org/10.1016/j.cad.2010.04.002

7. Krishnan, Karthika. "A Hypsometric Perspective in Comprehensing the Geomorphic Development of Tambraparni RiverBasin, Western Flank, South Western Ghats." International Journal of Humanities and Social Sciences (IJHSS) 4.5 (2015).

8. Nicolais, L., Sheikh-Ahmad, J. Y., \&Davim, J. P. (2012). Cutting and Machining of Polymer Composites. In Wiley Encyclopedia of Composites. https://doi.org/10.1002/9781118097298.weoc061

9. Amaro, P., Ferreira, P., \&Simões, F. (2020). Comparative analysis of different cutting milling strategies applied in duplex stainless steel. Procedia Manufacturing, 47, 517-524. https://doi.org/10.1016/j.promfg.2020.04.132

10. Huang, N., Jin, Y., Lu, Y., Yi, B., Li, X., \& Wu, S. (2020). Spiral toolpath generation method for pocket machining. Computers and Industrial Engineering, 139. https://doi.org/10.1016/j.cie.2019.106142

11. Brillhart, M., \& Botsis, J. (1992). Fatigue fracture behaviour of PEEK: 2. Effects of thickness and temperature. Polymer. https://doi.org/10.1016/0032-3861(92)90805-7

12. Zhao, H., \& Li, R. K. Y. (2006). Fracture behaviour of poly(ether ether ketone) films with different thicknesses. Mechanics of Materials. https://doi.org/10.1016/j.mechmat.2005.05.013

13. Standard Gage - Visual 250 - EuroPac Precision. (2020). Retrieved August 7, 2020, from http://www.europacprecision.com/products/optical-measurement/vision-systems/standard-gage-visual-250.htm

14. Roseline, S. SAGAYA, and EC HENRY Amirtharaj. "A new ranking of intuitionisticfuzzynumberswithdistancemethodbasedonthecircumcenter of centroids." International Journal of AppliedMathematics\&StatisticalSciences (IJAMSS) 2.4 (2013): 37-44.

15. Rae, P. J., Brown, E. N., \&Orler, E. B. (2007). The mechanical properties of poly(ether-ether-ketone) (PEEK) with emphasis on the large compressive strain response. Polymer. https://doi.org/10.1016/j.polymer.2006.11.032

16. Ketron® PEEK. (n.d.). Retrieved August 12, 2020, from https://www.mcam.com/na-es/productos/plasticosmaquinables/avanzados-325-425-f/ketronr-peek/ 
17. Carbide Compacts. (n.d.). Retrieved August 11, 2020, from https://www.kennametal.com/es/es/products/engineered-wearsolutions/engineered-components/carbide-compacts-and-substrates.html

18. Singh, S. S., et al. "Experimental Investigation of ThermalEfficiency of Boiling PotwithModified Surface Geometry." International Journal of Mechanical and Production Engineering Research and Development 8: 479-486.

19. TREE VMC-760/20 Centros de Maquinado Verticales - MachineTools.com. (n.d.). Retrieved August 12, 2020, from https://www.machinetools.com/es/models/leadwell-v-20i

20. Singh, V., Zutshi, S. Goel, U \& Murtaza, Q. (2020). Effect of process variables using square type cutting tool on surface roughness and residual stress of EN24 in an end-milling process. International Journal of Mechanical and Production Engineering Research and Development. 10(3), 147-158. https://doi.org/10.24247/ijmperdjun202014

21. Bhattacharya, A., Das, S., Majumder, P. \&Batish, A. (2009). Estimating the effect of cutting parameters on surface finish and power consumption during high speed machining of AISI1045 steel using TaguchidesignandANOVA.Production Engineering Research and Development.3, 31-40. https://doi.org/10.1007/s11740-008-0132-2 